\title{
Significance of chemotherapy-free interval and tumor regression grade in patients with recurrent esophageal squamous cell carcinoma receiving chemotherapy with fluorouracil and platinum after esophagectomy following preoperative chemotherapy
}

\author{
Mashiro Okunaka $^{1} \cdot$ Daisuke Kotani ${ }^{2} \cdot$ Ken Demachi $^{1} \cdot$ Hisashi Fujiwara ${ }^{3} \cdot$ Shingo Sakashita $^{4} \cdot$ Takayuki Yoshino $^{2}$. \\ Takeo Fujita ${ }^{3} \cdot$ Takashi Kojima $^{2}$
}

Received: 1 June 2021 / Accepted: 22 September 2021 / Published online: 5 October 2021

(c) The Author(s) 2021

\begin{abstract}
Background In Japan, standard treatment for locally advanced esophageal squamous cell carcinoma (ESCC) includes preoperative chemotherapy with fluorouracil plus cisplatin followed by esophagectomy. However, its efficacy is unclear in patients with recurrent disease with $<6$ months of chemotherapy-free interval (CFI) after preoperative chemotherapy followed by esophagectomy and in those with $\geq 6$ months of CFI and poor pathological response to prior preoperative chemotherapy. Method We retrospectively evaluated the efficacy of fluorouracil plus platinum in patients with recurrent ESCC who received preoperative chemotherapy followed by curative esophagectomy.

Results Among 105 patients with recurrent ESCC after preoperative chemotherapy followed by esophagectomy, a total of 55 patients received fluorouracil plus platinum for recurrent disease. Patients with a CFI $<6$ months $(n=20)$ had significantly shorter overall survival (OS) (median, 7.1 vs 14.5 months, $P=0.008)$ compared with those with a CFI $\geq 6$ months $(n=35)$. Multivariate analysis showed that OS was worse in patients with a CFI $<6$ months or a tumor regression grade (TRG) $\leq 1$ a . Furthermore, in patients with a CFI $\geq 6$ months, TRG $\leq 1$ a was associated with significantly shorter OS (11.1 months vs. not reached, $P=0.001$ ).

Conclusion Fluorouracil plus platinum was ineffective for recurrent ESCC in patients with a CFI $<6$ months and in those with a CFI $\geq 6$ months and a TRG $\leq 1 \mathrm{a}$. Alternate regimens including nivolumab or pembrolizumab might be considered for the treatment for recurrence in these patients.
\end{abstract}

Keywords Esophageal squamous cell carcinoma · Chemotherapy · Chemotherapy-free interval · Tumor regression grade

\section{Introduction}

Daisuke Kotani

dkotani@east.ncc.go.jp

1 Department of Pharmacy, National Cancer Center Hospital East, Kashiwa, Japan

2 Department of Gastrointestinal Oncology, National Cancer Center Hospital East, 6-5-1 Kashiwanoha, Kashiwa, Chiba 277-8577, Japan

3 Division of Esophageal Surgery, National Cancer Center Hospital East, Kashiwa, Japan

4 Division of Pathology, Exploratory Oncology Research and Clinical Trial Center, National Cancer Center Hospital East, Kashiwa, Japan
Esophageal cancer remains the sixth leading cause of cancer mortality worldwide $[1,2]$. Squamous cell carcinoma (SCC) accounts for over $90 \%$ of all esophageal cancer cases in East Asia, whereas adenocarcinoma is the dominant histological subtype in Western countries [3]. The Japanese Clinical Oncology Group (JCOG) 9907 trial, which compared preoperative chemotherapy with fluorouracil plus cisplatin followed by esophagectomy and esophagectomy followed by postoperative chemotherapy in patients with locally advanced esophageal SCC (ESCC), demonstrated the survival benefit of preoperative chemotherapy (5-year overall survival [OS] $55 \%$ vs $43 \%$, hazard ratio [HR] 0.73 , $P=0.04$ ) [4]. Based on the JCOG9907 trial, preoperative 
chemotherapy with fluorouracil plus cisplatin is a standard treatment regimen for locally advanced ESCC in Japan. Meanwhile, in the phase III (CROSS trial) conducted in Western countries, preoperative chemoradiotherapy consisting of carboplatin plus paclitaxel and preoperative concurrent radiotherapy with 41.4 Gy improved OS compared to surgery alone for locally advanced esophageal or esophagogastric cancer including both SCC and adenocarcinoma histologies [5, 6]. Therefore, preoperative chemotherapy or chemoradiotherapy followed by esophagectomy is a standard treatment for locally advanced ESCC. However, approximately $40-50 \%$ of patients recur within 3 years after esophagectomy with preoperative chemotherapy or chemoradiotherapy $[4,6]$.

Fluoropyrimidine plus oxaliplatin/cisplatin is the preferred first-line chemotherapy regimen for recurrent or metastatic esophageal or esophagogastric cancer including SCC and adenocarcinoma [2]. In gastric cancer patients with recurrent disease after curative surgery within 6 months after adjuvant $\mathrm{S}-1$ chemotherapy, the response rate to treatment with S-1 plus cisplatin is only $5 \%$, suggesting that S-1 plus cisplatin should be considered for patients with a recurrence-free interval $\geq 6$ months [7]. Meanwhile, the only retrospective small cohort study on recurrent ESCC suggested that seven patients with a chemotherapy-free interval $(\mathrm{CFI})<6$ months had a lack of sensitivity to the fluorouracil plus cisplatin regimen, which was administered as prior preoperative chemotherapy [8]. Since almost all clinical trials on first-line chemotherapy for recurrent or metastatic esophageal or esophagogastric cancer including SCC exclude patients with recurrent disease and a $\mathrm{CFI}<6$ months [9-11], the efficacy of fluorouracil plus platinum for recurrent disease in this patient population is unclear.

Tumor regression grade (TRG) has been reported as a prognostic marker for disease-free survival and OS in patients with ESCC as well as adenocarcinoma [12]. However, the association of TRG with the efficacy of fluorouracil plus platinum on recurrent disease and in patients having a CFI $>6$ months with unfavorable TRG is unclear.

Therefore, the present study aimed to investigate the efficacy of fluorouracil plus platinum according to CFI and TRG in patients with recurrent ESCC who received preoperative chemotherapy followed by curative esophagectomy.

\section{Methods}

\section{Study design and patients}

This retrospective study was designed to evaluate the efficacy of fluorouracil plus platinum regimen for patients with recurrent ESCC who received identical preoperative chemotherapy followed by curative esophagectomy. The study protocol was approved by the institutional review board of the National Cancer Center Hospital East (2020-589). Informed consent requirement was waived due to the retrospective observational design of the study, with opt-out opportunity provided at the institution's website.

The eligibility criteria were as follows: age, $\geq 20$ years; diagnosis of histologically proven recurrent ESCC after preoperative chemotherapy with fluorouracil plus cisplatin and subsequent curative esophagectomy (R0 or R1 according to the AJCC Cancer Staging Manual) [13]; Eastern Cooperative Oncology Group (ECOG) performance status (PS) score, $0-2$; adequate bone marrow and organ function to receive chemotherapy; evaluable lesions according to the Response Evaluation Criteria in Solid Tumors version 1.1 [14]; and treatment with fluorouracil plus platinum for recurrent ESCC between June 1, 2008 and March 31, 2020 at the National Cancer Center Hospital East.

\section{Study procedures}

Preoperative chemotherapy comprised two cycles of fluorouracil $\left(800 \mathrm{mg} / \mathrm{m}^{2}\right.$, days $\left.1-5\right)$ plus cisplatin $\left(80 \mathrm{mg} / \mathrm{m}^{2}\right.$, day 1) every 3 weeks or three cycles of fluorouracil $(750 \mathrm{mg} /$ $\mathrm{m}^{2}$, days $\left.1-5\right)$, cisplatin $\left(70 \mathrm{mg} / \mathrm{m}^{2}\right.$, day 1$)$, and docetaxel $\left(70 \mathrm{mg} / \mathrm{m}^{2}\right.$, day 1$)$ every 3 weeks. Surgery was performed by total or subtotal thoracic esophagectomy with three-field lymphadenectomy. Chemotherapy for recurrent disease comprised fluorouracil $\left(800 \mathrm{mg} / \mathrm{m}^{2}\right.$, days $\left.1-5\right)$ plus cisplatin $\left(80 \mathrm{mg} / \mathrm{m}^{2}\right.$, day 1$)$ every 4 weeks, fluorouracil $(800 \mathrm{mg} /$ $\mathrm{m}^{2}$, days $\left.1-5\right)$ plus nedaplatin $\left(80-90 \mathrm{mg} / \mathrm{m}^{2}\right.$, day 1$)$ every 4 weeks, and oxaliplatin $\left(85 \mathrm{mg} / \mathrm{m}^{2}\right.$, day 1$)$, leucovorin $\left(200 \mathrm{mg} / \mathrm{m}^{2}\right.$, day 1$)$, and fluorouracil $\left(400 \mathrm{mg} / \mathrm{m}^{2}\right.$ intravenous bolus on day 1 and $2400 \mathrm{mg} / \mathrm{m}^{2}$ by continuous 46-hinfusion on day 1) every 2 weeks. Dose modification and treatment interruption were determined by each investigator.

The following baseline characteristics were collected for each patient: age, sex, ECOG PS score, clinical stage at initial diagnosis, preoperative chemotherapy, CFI after last administration of preoperative chemotherapy, TRG, and recurrence sites.

\section{Outcomes}

The initiation of study treatment was defined as the start date of palliative chemotherapy for recurrent ESCC. Efficacy endpoints included progression-free survival (PFS), defined as the time interval from the initiation of study treatment to disease progression or death due to any cause; OS, defined as the time interval from the initiation of study treatment to death due to any cause; overall response rate (ORR), defined as the proportion of patients with complete or partial response to the study treatment; disease control rate (DCR), defined as the proportion of patients 
with complete or partial response plus stable disease lasting for $>6$ weeks from the initiation of study treatment; and CFI, defined as the time interval from last administration of preoperative chemotherapy to recurrence. Tumor response was assessed by each physician using the Response Evaluation Criteria in Solid Tumors version 1.1 every 8 weeks from the initiation of treatment until disease progression. Clinical and pathological stage was defined according to UICC-TNM 7th edition. Tumor regression was graded according to the Japanese Classification of Esophageal Cancer as follows: grade 0, no recognizable cytological or histological therapeutic effect; grade 1a, viable cancer cells accounting for two-thirds of tumor; grade $1 \mathrm{~b}$, viable cancer cells accounting for one-third or more but less than two-thirds of tumor; grade 2, viable cancer cells accounting for less than one-third of tumor; and grade 3 , no evidence of viable cancer cells [15].

\section{Statistical analysis}

PFS and OS were determined using Kaplan-Meier estimates, and rates between the treatment groups were compared using the log-rank test with a two-sided $P$ value of 0.05 . HRs and corresponding $95 \%$ confidence intervals (CIs) were determined using the Cox proportional hazards model. Comparisons of ORR, DCR, and safety outcomes between the treatment groups were performed using Fisher's exact test. Follow-up time was defined as the time from the initiation of study treatment until last follow-up for censored cases. The Cox regression model was used to assess the impact of CFI and TRG on PFS and OS, with adjustment for other factors which were considered to be associated with outcomes based on univariate logrank test. Statistical analyses were performed using SPSS version 22.0 (IBM, Armonk, NY, USA), and a two-sided $P$ value of $<0.05$ denoted statistical significance.

\section{Results}

\section{Patients}

During the study period, there were 105 patients with recurrent ESCC after preoperative chemotherapy followed by curative esophagectomy. Fifty patients were excluded due to salvage surgery or chemoradiotherapy $(N=38)$, other regimen than 5-FU plus platinum for initial palliative chemotherapy $(N=10)$, and lost to follow-up $(N=2)$. Finally, 55 patients who received fluorouracil plus platinum for recurrent disease were included in the full analysis set (Fig. 1). Among them, 26 (47.3\%) and 29 (52.7\%) patients received fluorouracil plus cisplatin and combination regimen with fluorouracil, cisplatin, and docetaxel, respectively, as preoperative chemotherapy; 39 of the 55 patients (70.9\%) completed the planned preoperative chemotherapy. Sixteen patients (29.1\%) discontinued preoperative chemotherapy due to disease progression $(n=10)$ or chemotherapeutic toxicity $(n=6)$. Twenty (36.4\%) and 35 patients (63.6\%) had a CFI of $<6$ and $\geq 6$ months, respectively. Meanwhile, TRG 0/1a and TRG $1 \mathrm{~b} / 2 / 3$ were in $38(69.1 \%)$ and 17 patients (30.9\%), respectively. Chemotherapy for recurrent disease included fluorouracil plus cisplatin, fluorouracil plus nedaplatin, and combination of oxaliplatin, leucovorin, and fluorouracil in $37(67.3 \%), 14(25.5 \%)$, and 4 (7.3\%), respectively.

Table 1 presents the comparison of baseline characteristics at the start of systemic chemotherapy for recurrent ESCC in patients with a CFI of $<6$ and $\geq 6$ months after the last administration of preoperative chemotherapy. There were no significant differences in baseline characteristics, including

Fig. 1 Flow diagram

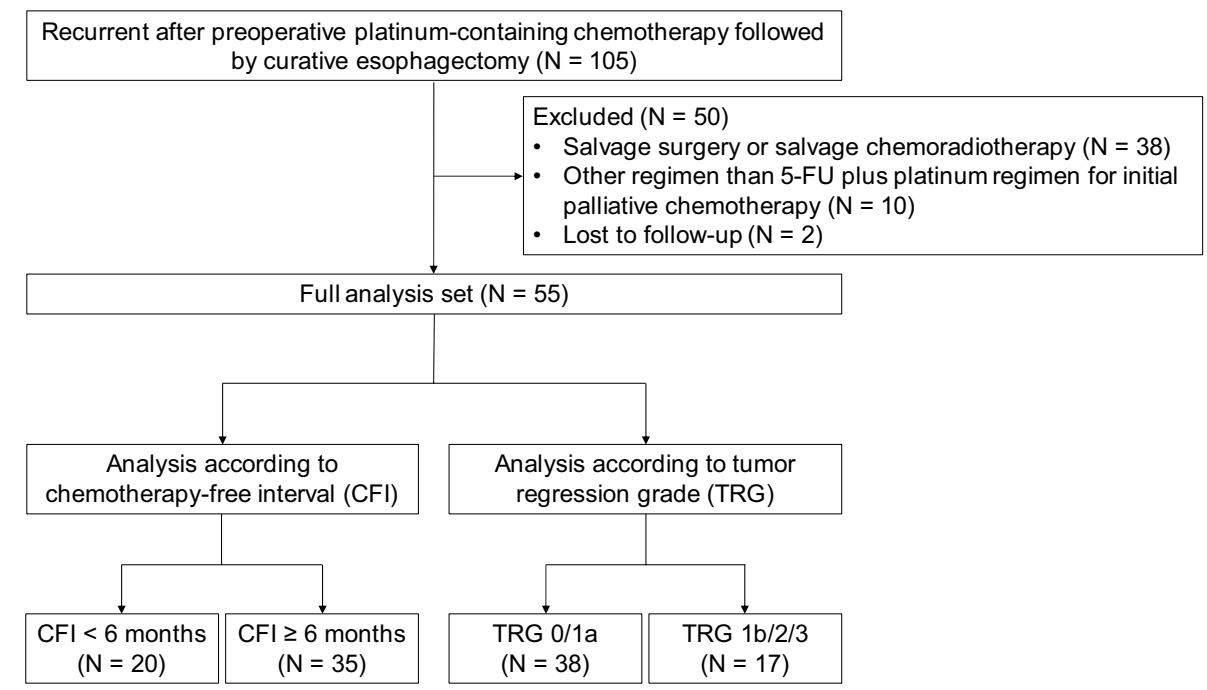


Table 1 Patient characteristics according to CFI

\begin{tabular}{|c|c|c|c|c|c|}
\hline & \multicolumn{2}{|c|}{$\mathrm{CFI}<6$ months } & \multicolumn{2}{|c|}{$\mathrm{CFI} \geq 6$ months } & \multirow[t]{2}{*}{$P$ value } \\
\hline & $N=20$ & $\%$ & $N=35$ & $\%$ & \\
\hline \multicolumn{6}{|l|}{ Age } \\
\hline Median (range) & $64(44-79)$ & & $68(50-78)$ & & 0.110 \\
\hline$\geq 65$ years old & 9 & 45.0 & 20 & 57.1 & 0.415 \\
\hline \multicolumn{6}{|l|}{ Gender } \\
\hline Male & 16 & 80.0 & 30 & 85.7 & 0.709 \\
\hline \multicolumn{6}{|l|}{ ECOG PS } \\
\hline 0 & 16 & 80.0 & 26 & 74.3 & 0.749 \\
\hline$>1$ & 4 & 20.0 & 9 & 25.7 & \\
\hline \multicolumn{6}{|l|}{ cStage } \\
\hline I & 0 & 0.0 & 3 & 8.6 & 0.326 \\
\hline II & 3 & 15.0 & 10 & 28.6 & \\
\hline III & 11 & 55.0 & 16 & 45.7 & \\
\hline IV & 6 & 30.0 & 6 & 17.1 & \\
\hline \multicolumn{6}{|c|}{ Preoperative chemotherapy } \\
\hline $\mathrm{FP}$ & 6 & 30.0 & 20 & 57.1 & 0.048 \\
\hline DCF & 14 & 70.0 & 15 & 42.9 & \\
\hline \multicolumn{6}{|l|}{ Extent of resection } \\
\hline R0 & 16 & 80.0 & 35 & 100.0 & 0.014 \\
\hline $\mathrm{R} 1$ & 4 & 20.0 & 0 & 0.0 & \\
\hline \multicolumn{6}{|l|}{ ypStage } \\
\hline I & 0 & 0.0 & 6 & 17.1 & 0.121 \\
\hline II & 5 & 25.0 & 10 & 28.6 & \\
\hline III & 9 & 45.0 & 15 & 42.9 & \\
\hline IV & 6 & 30.0 & 4 & 11.4 & \\
\hline \multicolumn{6}{|l|}{ TRG } \\
\hline $0 / 1 \mathrm{a}$ & 15 & 75.0 & 23 & 65.7 & 0.555 \\
\hline $1 b / 2 / 3$ & 5 & 25.0 & 12 & 34.3 & \\
\hline \multicolumn{6}{|c|}{ Number of recurrent site } \\
\hline 1 & 10 & 50.0 & 13 & 37.1 & 0.403 \\
\hline$>2$ & 10 & 50.0 & 22 & 62.9 & \\
\hline \multicolumn{6}{|l|}{ Site of recurrence } \\
\hline Liver & 7 & 35.0 & 9 & 25.7 & 0.543 \\
\hline Lung & 6 & 30.0 & 14 & 40.0 & 0.565 \\
\hline Lymph node & 12 & 60.0 & 25 & 71.4 & 0.551 \\
\hline Bone & 4 & 20.0 & 8 & 22.9 & 1.000 \\
\hline Others & 6 & 30.0 & 9 & 25.7 & 0.761 \\
\hline
\end{tabular}

ECOG PS Eastern Cooperative Oncology Group performance status

age, sex, ECOG PS score, clinical stage, pathological stage, TRG, and number and location of sites of recurrence, at the time of recurrent ESCC diagnosis. Regarding preoperative chemotherapy, the rate of combination chemotherapy with fluorouracil, cisplatin, and docetaxel was higher in patients with a CFI $<6$ months than in those with a CFI $\geq 6$ months (70.0\% vs $42.9 \%, P=0.048$ ). Likewise, Table 2 presents the baseline characteristics according to a TRG 0/1a and TRG $1 b / 2 / 3$ for preoperative chemotherapy. There were also no significant differences in baseline characteristics other than
Table 2 Patient characteristics according to TRG

\begin{tabular}{|c|c|c|c|c|c|}
\hline & \multicolumn{2}{|l|}{ TRG 0/1a } & \multicolumn{2}{|l|}{ TRG $1 \mathrm{~b} / 2 / 3$} & \multirow[t]{2}{*}{$P$ value } \\
\hline & $N=38$ & $\%$ & $N=17$ & $\%$ & \\
\hline \multicolumn{6}{|l|}{ Age } \\
\hline Median (range) & $65(44-79)$ & & $64(44-78)$ & & 0.539 \\
\hline$\geq 65$ years old & 20 & 52.6 & 9 & 52.9 & 1.000 \\
\hline \multicolumn{6}{|l|}{ Gender } \\
\hline Male & 33 & 86.8 & 13 & 76.5 & 0.435 \\
\hline \multicolumn{6}{|l|}{ ECOG PS } \\
\hline 0 & 29 & 76.3 & 13 & 76.5 & 1.000 \\
\hline$\geq 1$ & 9 & 23.7 & 4 & 23.5 & \\
\hline \multicolumn{6}{|l|}{ cStage } \\
\hline I & 3 & 7.9 & 0 & 0.0 & 0.066 \\
\hline II & 12 & 31.6 & 1 & 5.9 & \\
\hline III & 17 & 44.7 & 10 & 58.8 & \\
\hline IV & 6 & 15.8 & 6 & 35.3 & \\
\hline \multicolumn{6}{|c|}{ Preoperative chemotherapy } \\
\hline FP & 23 & 60.5 & 3 & 17.6 & 0.004 \\
\hline DCF & 15 & 39.5 & 14 & 82.4 & \\
\hline \multicolumn{6}{|c|}{ Extent of resection } \\
\hline R0 & 34 & 89.5 & 17 & 100.0 & 0.299 \\
\hline $\mathrm{R} 1$ & 4 & 10.5 & 0 & 0.0 & \\
\hline \multicolumn{6}{|l|}{ ypStage } \\
\hline I & 3 & 7.9 & 3 & 17.6 & 0.053 \\
\hline II & 8 & 21.1 & 7 & 41.2 & \\
\hline III & 21 & 55.3 & 3 & 17.6 & \\
\hline IV & 6 & 15.8 & 4 & 23.5 & \\
\hline \multicolumn{6}{|l|}{ CFI } \\
\hline$<6$ months & 15 & 39.5 & 5 & 29.4 & 0.555 \\
\hline$\geq 6$ months & 23 & 60.5 & 12 & 70.6 & \\
\hline \multicolumn{5}{|c|}{ Number of recurrent site } & 0.376 \\
\hline 1 & 14 & 36.8 & 9 & 52.9 & \\
\hline$\geq 2$ & 24 & 63.2 & 8 & 47.1 & \\
\hline \multicolumn{6}{|l|}{ Site of recurrence } \\
\hline Liver & 10 & 26.3 & 6 & 35.3 & 0.533 \\
\hline Lung & 13 & 34.2 & 7 & 41.2 & 0.763 \\
\hline Lymph node & 28 & 73.7 & 9 & 52.9 & 0.213 \\
\hline Bone & 9 & 23.7 & 3 & 17.6 & 0.735 \\
\hline Others & 11 & 28.9 & 4 & 23.5 & 0.754 \\
\hline
\end{tabular}

ECOG PS Eastern Cooperative Oncology Group performance status

preoperative chemotherapy regimen (combination chemotherapy with fluorouracil, cisplatin, and docetaxel, 39.5\% vs $82.4 \%, P=0.004)$.

\section{Efficacy}

Fifty-four patients discontinued the regimen with fluorouracil plus platinum for recurrent disease due to disease progression $(n=50)$ or chemotherapeutic toxicity $(n=4)$, and the study treatment was ongoing in one patient at last 
follow-up. The median PFS was 1.9 (95\% CI 1.6-2.2) months (Supplemental Fig. 1a). Eleven patients achieved complete response $(n=1)$ or partial response $(n=10)$, and 12 patients were determined to have stable disease, with an ORR of $20.0 \%$ and DCR of $41.8 \%$. During the study period, 38 patients $(69.1 \%)$ died. The median OS was 11.4 (95\% CI 7.5-15.3) months during a median follow-up period of 21.7 (95\% CI 19.2-24.2) months (Supplemental Fig. 1b). Thirty-five patients $(63.6 \%)$ received subsequent antitumor therapy, including taxanes $(n=31)$, investigational agents in clinical trials $(n=8)$, and anti-programmed cell death 1 antibody $(n=6)$.

\section{Impact of CFI and TRG}

Patients with a CFI $<6$ months had shorter PFS with marginal significance (median 1.8 vs. 3,4 months, HR 1.80 , 95\% CI $0.97-3.34, P=0.055)$ and significantly shorter OS (median 7.1 vs. 14.5 months, HR 2.42, 95\% CI 1.23-4.77, $P=0.008)$ compared with those with a CFI $\geq 6$ months (Fig. 2). In addition, albeit not statistically significant, the ORR was lower in patients with a CFI $<6$ months than in those with a CFI $\geq 6$ months $(10.0 \%$ vs. $25.7 \%, P=0.293)$ (Table 3).

TRG $\leq 1$ a was associated with significantly shorter PFS (median 1.7 vs. 6.8 months, HR 3.32, 95\% CI 1.66-6.66, $P<0.001$ ), shorter OS (median 9.3 months vs. not reached, HR 4.97, 95\% CI 2.04-12.08, $P<0.001)$ and lower ORR (7.9\% vs. $47.1 \%, P<0.001)$ compared with TRG $\geq 1 \mathrm{~b}$ (Fig. 3).

By multivariate analysis for PFS, TRG $\leq 1$ a was independently associated with poor outcome (Table 4). Additionally, in multivariate analyses for OS, only $\mathrm{TRG} \leq 1 \mathrm{a}$ and $\mathrm{CFI}<6$ months were independent poor prognostic factors (Table 5). Furthermore, even after excluding ten patients who were experienced disease progression during preoperative chemotherapy, TRG $\leq 1 \mathrm{a}$ and $\mathrm{CFI}<6$ months were still
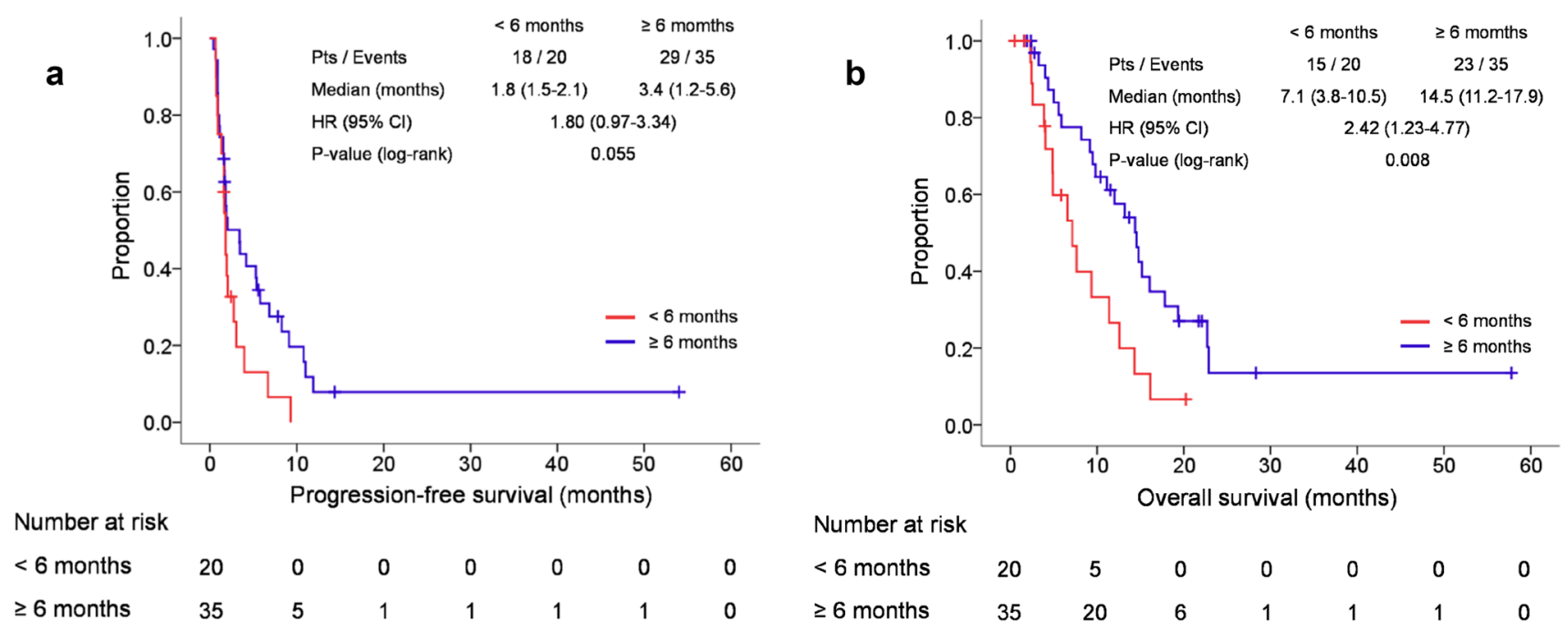

Fig. 2 a Kaplan-Meier estimates of progression-free survival according to CFI. CFI, chemotherapy-free interval; HR, hazard ratio. b KaplanMeier estimates of overall survival according to CFI. CFI chemotherapy-free interval; $H R$ hazard ratio

Table 3 Response rate according to CFI and TRG

\begin{tabular}{|c|c|c|c|c|c|c|c|c|c|c|}
\hline & \multicolumn{4}{|c|}{$\mathrm{CFI}<6$ months } & \multirow[t]{3}{*}{$P$ value } & \multicolumn{4}{|c|}{$\mathrm{CFI} \geq 6$ months } & \multirow[t]{3}{*}{$P$ value } \\
\hline & \multicolumn{2}{|c|}{ Grade $0 / 1 \mathrm{a}$} & \multicolumn{2}{|c|}{ Grade $1 \mathrm{~b} / 2 / 3$} & & \multicolumn{2}{|c|}{ Grade $0 / 1 \mathrm{a}$} & \multicolumn{2}{|c|}{ Grade $1 \mathrm{~b} / 2 / 3$} & \\
\hline & $N=15$ & $\%$ & $N=5$ & $\%$ & & $N=23$ & $\%$ & $N=12$ & $\%$ & \\
\hline CR & 0 & 0.0 & 0 & 0.0 & & 0 & 0.0 & 1 & 8.3 & \\
\hline PR & 1 & 6.7 & 1 & 20.0 & & 2 & 8.7 & 6 & 50.0 & \\
\hline SD & 3 & 20.0 & 1 & 20.0 & & 5 & 21.7 & 3 & 25.0 & \\
\hline PD & 11 & 73.3 & 3 & 60.0 & & 16 & 69.6 & 2 & 16.7 & \\
\hline ORR & 1 & 6.7 & 1 & 20.0 & 0.447 & 2 & 8.7 & 7 & 58.3 & 0.003 \\
\hline DCR & 4 & 26.7 & 2 & 40.0 & 0.613 & 7 & 30.4 & 10 & 83.3 & 0.005 \\
\hline
\end{tabular}

$C R$ complete response, $P R$ partial response, $S D$ stable disease, $P D$ progressive disease, $O R R$ objective response rate, $D C R$ disease control rate 

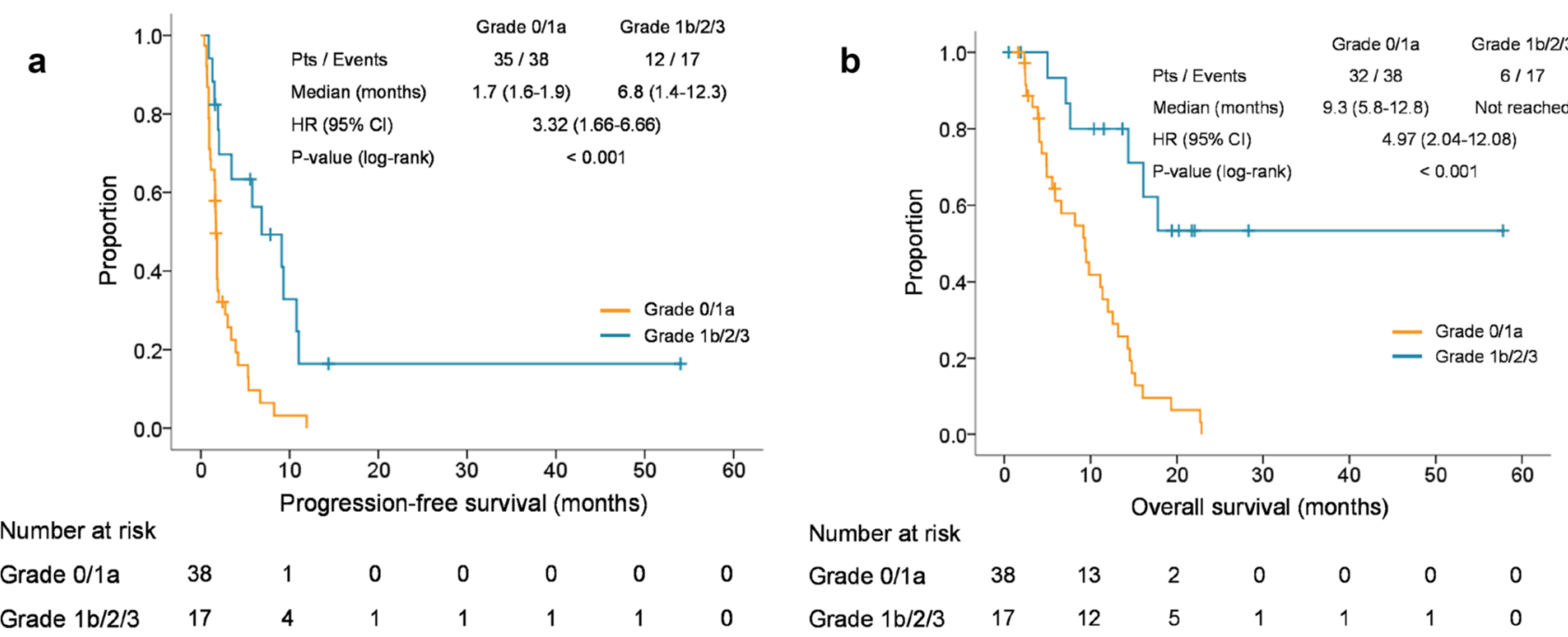

Fig. 3 a Kaplan-Meier estimates of progression-free survival according to TRG. TRG tumor regression grade; $H R$ hazard ratio. b Kaplan-Meier estimates of overall survival according to TRG. TRG tumor regression grade; $H R$ hazard ratio

Table 4 Univariate and multivariate analysis for progression-free survival

\begin{tabular}{|c|c|c|c|c|c|}
\hline \multirow[t]{2}{*}{ Variables } & \multirow[t]{2}{*}{ Category } & \multicolumn{2}{|l|}{ Univariate analysis } & \multicolumn{2}{|l|}{ Multivariate analysis } \\
\hline & & HR (95\% CI) & $P$ value & $\mathrm{HR}(95 \% \mathrm{CI})$ & $P$ value \\
\hline Age & $\geq 65$ vs $<65$ & $0.743(0.414-1.335)$ & 0.320 & & \\
\hline Gender & Male vs female & $0.681(0.316-1.468)$ & 0.326 & & \\
\hline ECOG PS & 0 vs $\geq 1$ & $0.952(0.493-1.838)$ & 0.882 & & \\
\hline cStage & I-II vs III-IV & $1.069(0.576-1.983)$ & 0.833 & & \\
\hline Preoperative chemotherapy & FP vs DCF & $1.155(0.650-2.049)$ & 0.624 & & \\
\hline Extent of resection & R0 vs R1 & $0.769(0.235-2.514)$ & 0.664 & & \\
\hline ypStage & I-II vs III-IV & $0.663(0.364-1.208)$ & 0.179 & $0.965(0.501-1.862)$ & 0.916 \\
\hline TRG & $0 / 1 \mathrm{a}$ vs $1 \mathrm{~b} / 2 / 3$ & $3.320(1.656-6.656)$ & 0.001 & $3.965(1.843-8.529)$ & $<0.001$ \\
\hline CFI (months) & $<6 \mathrm{vs} \geq 6$ & $1.801(0.972-3.339)$ & 0.062 & $1.825(0.956-3.483)$ & 0.068 \\
\hline Number of recurrent sites & $\geq 2$ vs 1 & $2.326(1.256-4.310)$ & 0.007 & $1.946(0.789-4.785)$ & 0.149 \\
\hline \multirow[t]{5}{*}{ Site of recurrence } & Liver & $0.975(0.520-1.828)$ & 0.937 & & \\
\hline & Lung & $1.576(0.866-2.868)$ & 0.136 & $1.812(0.934-3.516)$ & 0.079 \\
\hline & Lymph node & $1.948(1.022-3.714)$ & 0.043 & $1.228(0.485-3.108)$ & 0.665 \\
\hline & Bone & $1.032(0.524-2.029)$ & 0.928 & & \\
\hline & Others & $1.420(0.723-2.789)$ & 0.309 & & \\
\hline
\end{tabular}

independent poor prognostic factors for OS in multivariate analysis (Supplemental Table 1).

Among the patients with a $\mathrm{CFI}<6$ months, there were no significant differences in PFS and OS between the patients with a $\mathrm{TRG} \leq 1 \mathrm{a}$ and $\geq 1 \mathrm{~b}$ (PFS, median 1.6 vs. 2.0 months, respectively, HR 2.04, 95\% CI 0.58-7.15, $P=0.253$; OS, median 4.9 vs. 7.6 months, respectively, HR 3.87, 95\% CI 0.84-17.84, $P=0.064$ ) (Fig. 4). Furthermore, although a trend for lower response was observed in patients with a TRG $\leq 1$ a compared to in those with a
TRG $\geq 1 \mathrm{~b}(6.7 \%$ vs $20.0 \%)$, there was no significant difference $(P=0.447)$ (Table 3$)$. Conversely, among the patients with a CFI $\geq 6$ months, the patients with a TRG $\leq 1 \mathrm{a}$ had significantly shorter PFS and OS compared to those with a TRG $\geq 1 \mathrm{~b}$ (PFS, median 1.8 vs. 9.1 months, HR 3.69, 95\% CI $1.57-8.71, P=0.002$; OS, median 11.1 months vs. not reached, HR 6.40, 95\% CI 1.88-21.78, $P=0.001$ ) (Fig. 4). Furthermore, the ORR was significantly lower in patients with a TRG $\leq 1$ a compared to those with a TRG $\geq 1 \mathrm{~b}(8.7 \%$ vs. $58.3 \%, P=0.003$ ) (Table 3 ). 
Table 5 Univariate and multivariate analysis for overall survival

\begin{tabular}{|c|c|c|c|c|c|}
\hline \multirow[t]{2}{*}{ Variables } & \multirow[t]{2}{*}{ Category } & \multicolumn{2}{|l|}{ Univariate analysis } & \multicolumn{2}{|l|}{ Multivariate analysis } \\
\hline & & $\mathrm{HR}(95 \% \mathrm{CI})$ & $P$ value & HR (95\% CI) & $P$ value \\
\hline Age & $\geq 65$ vs $<65$ & $1.137(0.597-2.166)$ & 0.696 & & \\
\hline Gender & Male vs Female & $1.253(0.486-3.236)$ & 0.640 & & \\
\hline ECOG PS & 0 vs $\geq 1$ & $0.932(0.447-1.939)$ & 0.850 & & \\
\hline cStage & I-II vs III-IV & $1.206(0.615-2.364)$ & 0.586 & & \\
\hline Preoperative chemotherapy & FP vs DCF & $1.326(0.696-2.532)$ & 0.390 & & \\
\hline Extent of resection & R0 vs R1 & $0.270(0.092-0.790)$ & 0.017 & $0.787(0.237-2.614)$ & 0.696 \\
\hline ypStage & I-II vs III-IV & $0.609(0.313-1.186)$ & 0.145 & $0.941(0.465-1.906)$ & 0.866 \\
\hline TRG & $0 / 1 \mathrm{a}$ vs $1 \mathrm{~b} / 2 / 3$ & $4.968(2.044-12.075)$ & $<0.001$ & $5.235(2.079-13.184)$ & $<0.001$ \\
\hline CFI (months) & $<6$ vs $\geq 6$ & $2.421(1.229-4.766)$ & 0.011 & $2.590(1.193-5.619)$ & 0.016 \\
\hline Number of recurrent sites & $\geq 2$ vs 1 & $1.279(0.666-2.451)$ & 0.461 & & \\
\hline \multirow[t]{5}{*}{ Site of recurrence } & Liver & $0.841(0.408-1.733)$ & 0.639 & & \\
\hline & Lung & $0.894(0.457-1.750)$ & 0.743 & & \\
\hline & Lymph node & $1.454(0.710-2.976)$ & 0.306 & & \\
\hline & Bone & $1.026(0.449-2.346)$ & 0.951 & & \\
\hline & Others & $1.501(0.721-3.125)$ & 0.277 & & \\
\hline
\end{tabular}

\section{Discussion}

The results of this retrospective study, which evaluated the efficacy of combination chemotherapy with fluorouracil plus platinum in patients with recurrent ESCC who previously received preoperative chemotherapy followed by curative esophagectomy, indicate that CFI and TRG should be taken into consideration in deciding on whether patients should receive chemotherapy with fluorouracil plus platinum for recurrent ESCC after esophagectomy with preoperative chemotherapy.

In patients with ESCC, the value of palliative chemotherapy remains unclear. The European Society of Medical Oncology clinical practice guidelines indicate that best supportive care or palliative monotherapy should be considered in these patients [16]. More recently, although the pan-Asian adapted European Society of Medical Oncology clinical practice guidelines referred that combination chemotherapy is the preferred option for fit patients [17], standard chemotherapy regimen was not defined in the guideline. Conversely, in the recent KEYNOTE-590 trial, which demonstrated the superiority of pembrolizumab plus chemotherapy over chemotherapy alone as first-line chemotherapy for esophageal cancer, combination chemotherapy with fluorouracil and cisplatin was considered as a standard first-line chemotherapy for advanced ESCC [18]. Therefore, platinum-based combination chemotherapy has been a community standard as first-line chemotherapy for advanced ESCC despite insufficient evidence. Furthermore, most clinical trials, including the KEYNOTE-590 trial, excluded patients with a $\mathrm{CFI}<6$ months. However, evidence is lacking regarding the exclusion of patients with recurrent disease and a $\mathrm{CFI}<6$ months from receiving first-line chemotherapy [9-11].

The present study demonstrated that the outcomes were unfavorable in patients with a $\mathrm{CFI}<6$ months compared to those with a CFI $\geq 6$ months. Considering the significantly shorter OS and relatively lower ORR of $10.5 \%$ and a shorter median PFS of 1.8 months in patients with CFI $<6$ months, other regimens should be considered as alternative chemotherapy in those patients. In fact, the ATTRACTION-3 [19] and KEYNOTE-181 [20] trials, which evaluated nivolumab and pembrolizumab, respectively, in a second-line setting for esophageal cancer, included patients with disease recurrence within 6 months from the last administration of preoperative systemic chemotherapy or chemoradiotherapy. These trials revealed that the ORRs were $19 \%$ and $22 \%$ with nivolumab in all ESCC patients and pembrolizumab in patients with ESCC who had a PD-L1 combined positive score $\geq 10$, respectively.

We also demonstrated the significance of TRG in patients receiving chemotherapy for recurrent ESCC. TRG $\leq 1$ a was associated with significantly shorter PFS and OS and was an independent poor prognostic factor for PFS and OS by univariate and multivariate analyses. Our study suggested that patients with $\mathrm{TRG} \leq 1 \mathrm{a}$ were primary insensitive to fluorouracil plus platinum regimens. In fact, only two of the patients with a CFI $\geq 6$ months and $T R G \leq 1$ a partial responded to the study treatment (ORR of $8.7 \%$ ). Considering an ORR of $29.3 \%$ for first-line chemotherapy in the control group of the KEYNOTE-590 trial [18], alternative regimens including nivolumab or pembrolizumab might be 


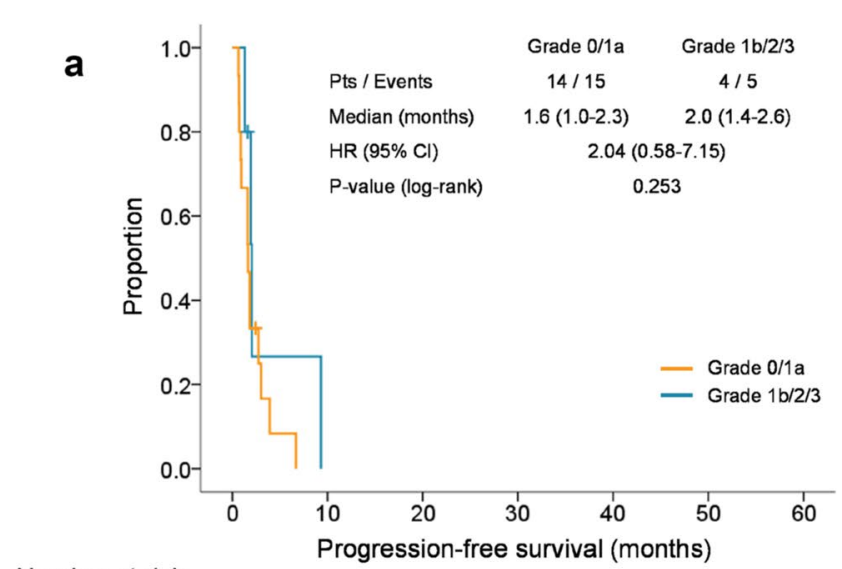

Number at risk

$\begin{array}{lccccccc}\text { Grade } 0 / 1 \mathrm{a} & 15 & 0 & 0 & 0 & 0 & 0 & 0 \\ \text { Grade } 1 \mathrm{~b} / 2 / 3 & 5 & 0 & 0 & 0 & 0 & 0 & 0\end{array}$

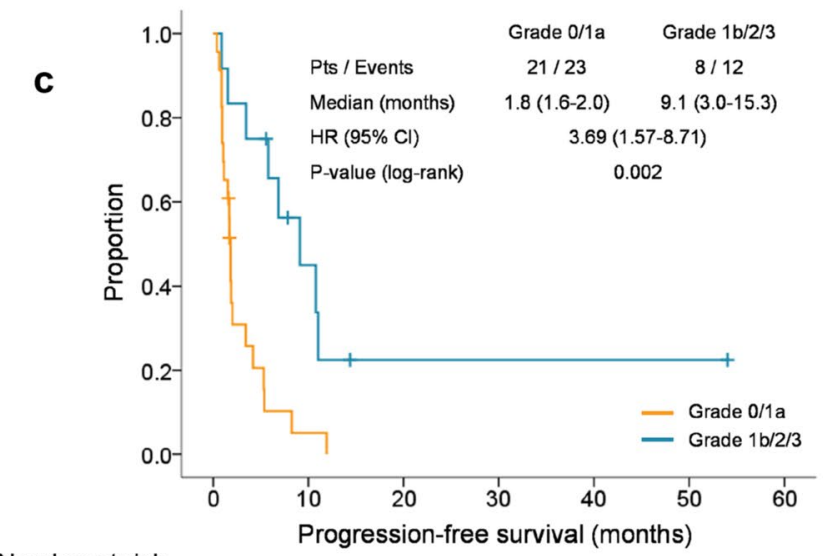

Number at risk

$\begin{array}{llllllll}\text { Grade } 0 / 1 \mathrm{a} & 23 & 1 & 0 & 0 & 0 & 0 & 0 \\ \text { Grade } 1 \mathrm{~b} / 2 / 3 & 12 & 4 & 1 & 1 & 1 & 1 & 0\end{array}$

Fig. 4 a Kaplan-Meier estimates of progression-free survival according to TRG in patients with a $\mathrm{CFI}<6$ months. CFI chemotherapyfree interval; $T R G$ tumor regression grade; HR, hazard ratio. b Kaplan-Meier estimates of overall survival according to TRG in patients with a CFI $<6$ months. $C F I$ chemotherapy-free interval; $T R G$ tumor regression grade; $H R$ hazard ratio. c Kaplan-Meier estimates

considered in these patients. In contrast, for patients with a $\mathrm{CFI}<6$ months and TRG $\geq 1 \mathrm{~b}$, although only one of the five patients responded to the study treatment (ORR of 20.0\%), fluorouracil plus platinum is not generally recommended based on the extremely short median PFS of 2.0 months.

The present study has several limitations. First, this was a non-randomized retrospective study with a limited sample size performed in a single institution. In particular, preoperative chemotherapy regimens were imbalanced between the groups. However, we performed the multivariate analyses, confirming the independent prognostic factor of CFI and TRG for OS in patients receiving palliative chemotherapy for recurrent ESCC. Second, treatment

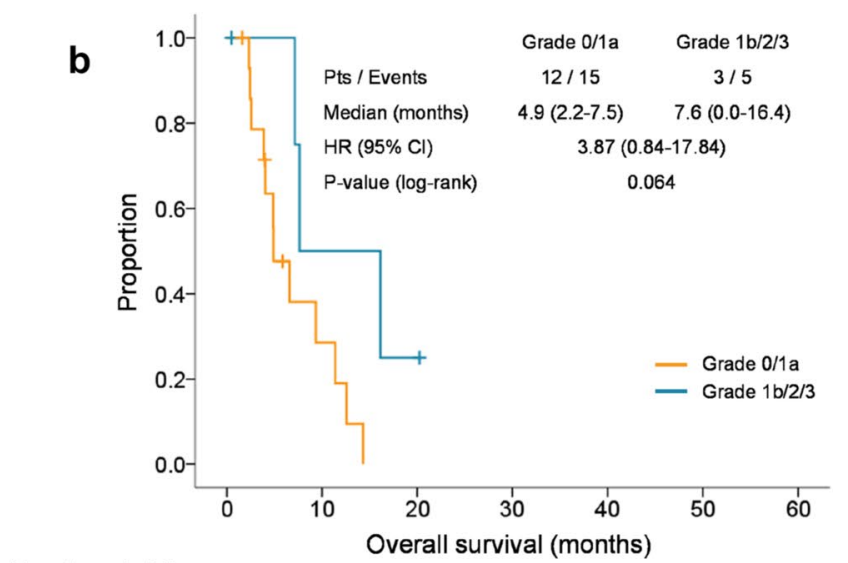

Number at risk

$\begin{array}{lccccccc}\text { Grade } 0 / 1 \mathrm{a} & 15 & 3 & 0 & 0 & 0 & 0 & 0 \\ \text { Grade } 1 \mathrm{~b} / 2 / 3 & 5 & 2 & 1 & 0 & 0 & 0 & 0\end{array}$

Number at risk

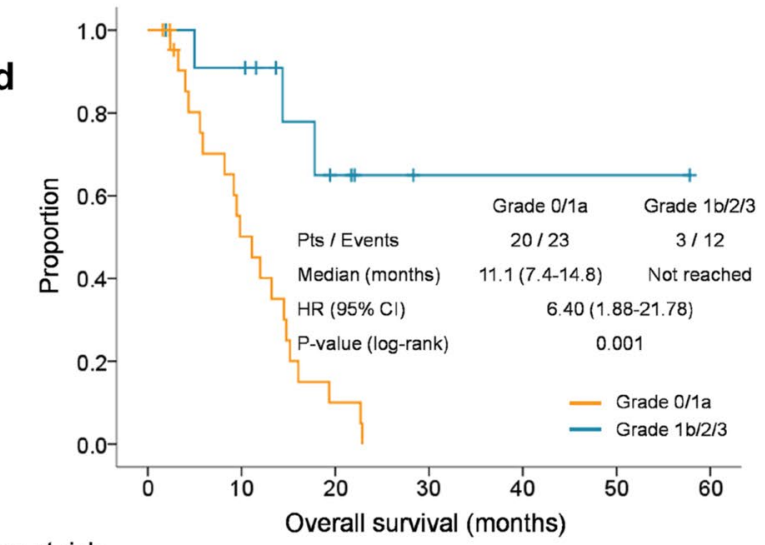

$\begin{array}{llllllll}\text { Grade 0/1a } & 23 & 10 & 2 & 0 & 0 & 0 & 0 \\ \text { Grade } 1 \mathrm{~b} / 2 / 3 & 12 & 10 & 4 & 1 & 1 & 1 & 0\end{array}$

of progression-free survival according to TRG in patients with a CFI $\geq 6$ months. $C F I$ chemotherapy-free interval; $T R G$ tumor regression grade; $H R$, hazard ratio. d Kaplan-Meier estimates of overall survival according to TRG in patients with a CFI $\geq 6$ months $C F I$ chemotherapy-free interval; $T R G$ tumor regression grade; $H R$ hazard ratio

after recurrence was selected individually by each physician. Patients who received other regimens for recurrent disease might not be fit for combination regimen or may experience a clinically poor response to preoperative treatment with a regimen containing fluorouracil and platinum. Finally, all patients received preoperative chemotherapy, not chemoradiotherapy, as a standard preoperative treatment for ESCC in Japan.

In conclusion, in this largest cohort study to evaluate the efficacy of combination chemotherapy with fluorouracil plus platinum in patients with recurrent ESCC who previously received preoperative chemotherapy followed by curative esophagectomy, fluorouracil plus platinum 
for recurrent ESCC was ineffective in patients with a $\mathrm{CFI}<6$ months and in those with a CFI $\geq 6$ months and a $T R G \leq 1$ a. These patients may be considered to receive alternative regimens including nivolumab and pembrolizumab for the treatment of recurrent disease.

Supplementary Information The online version contains supplementary material available at https://doi.org/10.1007/s10388-021-00885-3.

Acknowledgements The authors would like to thank Enago (www. enago.jp) for the English language review.

Funding This study was not funded.

\section{Declarations}

Ethical statement All procedures performed in studies involving human participants were in accordance with the ethical standards of the institutional and/or national research committee and with the 1964 Helsinki declaration and its later amendments or comparable ethical standards.

Conflict of interest MO has nothing to disclose. DK reports honoraria from Taiho, Ono, Daiichi-Sankyo, Pfizer, Takeda, Lilly, Merck Biopharma, MSD, Bristol-Myers Squibb, Chugai, and Sysmex. KD has nothing to disclose. HF has nothing to disclose. SS has nothing to disclose. TY reports receiving research funding from Taiho, Sumitomo Dainippon, Ono, Chugai, Amgen, Parexel international, MSD, Daiichi-Sankyo, and Sanofi. TF has nothing to disclose. TK reports receiving research funding from MSD, Ono, Bristol-Myers Squibb, Astellas Amgen, Taiho, Chugai, and Shionogi; and honoraria from Ono, Bristol-Myers Squibb, MSD, Astellas, Merck, and Oncolys.

Informed consent Informed consent requirement was waived due to the retrospective observational design of the study, with opt-out opportunity provided at the institution's website.

Open Access This article is licensed under a Creative Commons Attribution 4.0 International License, which permits use, sharing, adaptation, distribution and reproduction in any medium or format, as long as you give appropriate credit to the original author(s) and the source, provide a link to the Creative Commons licence, and indicate if changes were made. The images or other third party material in this article are included in the article's Creative Commons licence, unless indicated otherwise in a credit line to the material. If material is not included in the article's Creative Commons licence and your intended use is not permitted by statutory regulation or exceeds the permitted use, you will need to obtain permission directly from the copyright holder. To view a copy of this licence, visit http://creativecommons.org/licenses/by/4.0/.

\section{References}

1. Ferlay J, Soerjomataram I, Ervik M, et al. GLOBOCAN 2012 v11, cancer incidence and mortality worldwide: IARS cancer base no 11. Lyon: International Agency for Research on Cancer; 2014.

2. National Comprehensive Cancer Network. NCCN clinical practice guidelines in oncology esophageal and esophagogastric junction cancers. Version 4. 2021. Available online: https://www.ncen.org/ professionals/physician_gls/pdf/esophageal.pdf. Accessed 5 Oct 2021.

3. Malhotra GK, Yanala U, Ravipati A, Follet M, Vijayakumar M, Are C. Global trends in esophageal cancer. J Surg Oncol. 2017;115:564-79.

4. Ando N, Kato H, Igaki $\mathrm{H}$, et al. a randomized trial comparing postoperative adjuvant chemotherapy with cisplatin and 5-fluorouracil versus preoperative chemotherapy for localized advanced squamous cell carcinoma of the thoracic esophagus (JCOG9907). Ann Surg Oncol. 2012;19:68-74.

5. Van Hagen P, Hulshof MC, van Lanschot JJ, et al. Preoperative chemoradiotherapy for esophageal or junctional cancer. N Engl J Med. 2012;366:2074-84.

6. Shapiro J, van Lanschot JJB, Hulshof MCCM, et al. Neoadjuvant chemoradiotherapy plus surgery versus surgery alone for oesophageal or junctional cancer (CROSS): long-term results of a randomised controlled trial. Lancet Oncol. 2015;16:1090-8.

7. Shitara K, Morita S, Fujitani K, et al. Combination chemotherapy with S-1 plus cisplatin for gastric cancer that recurs after adjuvant chemotherapy with S-1: multi-institutional retrospective analysis. Gastric Cancer. 2012;15:245-51.

8. Takashima A, Shirao K, Hirashima Y, et al. Chemosensitivity of patients with recurrent esophageal cancer receiving perioperative chemotherapy. Dis Esophagus. 2008;21:607-11.

9. Kato K, Shah MA, Enzinger P, et al. KEYNOTE-590: Phase III study of first-line chemotherapy with or without pembrolizumab for advanced esophageal cancer. Future Oncol. 2019;15:1057-66.

10. Kato K, Muro K, Ando N, et al. A phase II study of nedaplatin and 5-fluorouracil in metastatic squamous cell carcinoma of the esophagus: the Japan Clinical Oncology Group (JCOG) Trial (JCOG 9905-DI). Esophagus. 2014;11:183-8.

11. Kataoka K, Tsushima T, Mizusawa J, et al. A randomized controlled Phase III trial comparing 2-weekly docetaxel combined with cisplatin plus fluorouracil (2-weekly DCF) with cisplatin plus fluorouracil $(\mathrm{CF})$ in patients with metastatic or recurrent esophageal cancer: rationale, design and methods of Japan Clinical Oncology Group study JCOG1314 (MIRACLE study). Jpn J Clin Oncol. 2015;45:494-8.

12. Takeda FR, Tustumi F, de Almeida OC, et al. Prognostic value of tumor regression grade based on Ryan score in squamous cell carcinoma and adenocarcinoma of esophagus. Ann Surg Oncol. 2020;27:1241-7.

13. Rice TW, Kelsen D, Blackstone EH, et al. Esophagus and esophagogastric junction. In: Amin MB, Edge S, Greene F, et al., editors. AJCC cancer staging manual. 8th ed. New York: Springer; 2017. p. 185-202.

14. Eisenhauer EA, Therasse P, Bogaerts J, et al. New response evaluation criteria in solid tumours: revised RECIST guideline (version 1.1). Eur J Cancer. 2016;62:132-7.

15. Japan Esophageal Society. Japanese classification of esophageal cancer, 11th Edition: part I. Esophagus. 2017;14:1-36.

16. Lordick F, Mariette C, Haustermans K, Obermannova R, Arnold D, ESMO Guidelines Committee. Oesophageal cancer ESMO clinical practice guidelines for diagnosis treatment and followup. Ann Oncol. 2016;27:V50-7.

17. Muro K, Lordick F, Tsushima T, et al. Pan-Asian adapted ESMO Clinical Practice Guidelines for the management of patients with metastatic oesophageal cancer: a JSMO-ESMO initiative endorsed by CSCO, KSMO, MOS SSO and TOS. Ann Oncol. 2019;30:34-43.

18. Kato K, Sun JM, Shah MA, et al. LBA8_PR Pembrolizumab plus chemotherapy versus chemotherapy as first-line therapy in patients with advanced esophageal cancer: The phase $3 \mathrm{KEY}$ NOTE-590 study. Ann Oncol. 2020;31:s1192-3. 
19. Kato K, Cho BC, Takahashi M, et al. Nivolumab versus chemotherapy in patients with advanced oesophageal squamous cell carcinoma refractory or intolerant to previous chemotherapy (ATT RACTION-3): a multicentre, randomised, open-label, phase 3 trial. Lancet Oncol. 2019;20:1506-17.
20. Kojima T, Shah MA, Muro K, et al. Randomized phase III KEYNOTE-181 study of pembrolizumab versus chemotherapy in advanced esophageal cancer. J Clin Oncol. 2020;38:4138-48.

Publisher's Note Springer Nature remains neutral with regard to jurisdictional claims in published maps and institutional affiliations. 